\title{
Nursing and medical students near-peer activity in the anatomy laboratory: format for success
}

This article was published in the following Dove Press journal:

Advances in Medical Education and Practice

\author{
Patricia Alfaro' \\ Sandie S Larouche' \\ Nicole M Ventura (iD ${ }^{2,3}$ \\ Jonathan Hudon (iD) ${ }^{2}$ \\ Geoffroy PJC Noel (iD) 2,3 \\ 'Ingram School of Nursing, McGill \\ University, Montreall, Quebec, Canada; \\ ${ }^{2}$ Division of Anatomical Sciences, \\ Department of Anatomy and Cell \\ Biology, McGill University, Montreal, \\ Quebec, Canada; ${ }^{3}$ nstitute of Health \\ Sciences Education, Faculty of Medicine, \\ McGill University, Montreal, Quebec, \\ Canada
}

Background/aims: An anatomy interprofessional near-peer learning activity (AIP-NPLA) between nursing and medical students was piloted to assess its implementability. This study aimed to: (1) identify key factors of feasibility and (2) describe student-group perceptions of their experience of the interprofessional education (IPE) activity.

Methods: A total of 59 medical and 179 nursing students participated in the AIP-NPLA whereby medical students were asked to facilitate and lead group discussions with their nursing students colleagues on an anatomical topic using a donor cadaver. Each AIP-NPLA session lasted a total of two hours. A mixed methods approach was employed using both quantitative and qualitative means of assessment. Variables such as Readiness for Interprofessional Learning, Professional Self-Identity, Clinical Teaching Preference, and Near-Peer Teaching and Learning Experience were assessed quantitatively using validated surveys. Qualitative measures included thematic content analysis of focus group interviews conducted following the AIP-NPLA to capture the perceptions of the student groups' experience in the IPE activity.

Results: The results of this investigation demonstrated that there are key factors to consider when designing successful and sustainable IPE activities; the level of clinical exposure and therefore student-group pairing based on professional self-identify scores, optimal tutor-totutee group ratios and an activity format that maintained an informal, flexible and free forum for discussion on a topic of common knowledge. Focus group interviews also revealed reflections on professional stereotypes.

Conclusion: These findings suggest that early implementation of IPE activities outside of a clinical setting are beneficial and can foster both learning from one another and positive perceptions of interprofessional roles when carefully designed.

Keywords: interprofessional, anatomy, professional identity, near-peer learning, healthprofessional education

\section{Introduction}

Efficient healthcare delivery requires providers to cross professional barriers and collaborate with other disciplines. ${ }^{1}$ Nurses and physicians are two groups of healthcare professionals that are required to work in collaboration for the provision of safe patient care. Yet these two groups have traditionally been educated separately with limited opportunities to interact before entering the clinical setting. Henceforth, there is an increasing trend to incorporate interprofessional education (IPE) at the university level. ${ }^{2}$

IPE has been shown to allow students from different professional programs to learn with, about, and from each other, which, in turn, improves communication
Correspondence: Geoffroy PJC Noel McGill University, 3640 University St. H3A 0C7, Montreal, Quebec, Canada Email geoffroy.noel@mcgill.ca 
across professions and enhances patient outcomes. ${ }^{3-5}$ Many IPE models and frameworks exist, yet best practices for, and the long-term outcomes of, IPE strategies remain ill-defined. ${ }^{6}$ Thus, there is a need for educators to continue to develop and evaluate the value of IPE in their respective curricula.

There are many reports of IPE trials where students enrolled in different health professional programs are being taught by the same lecturer and/or in the same classroom. ${ }^{7-9}$ Studies on the implementation of such learning activities reported student concerns about large class sizes and teacher bias in favour of a subgroup. ${ }^{10,11}$ As an alternative approach to conducting IPE in large classes, pre-qualification undergraduate students from different health science programs have recently been suggested as a potential untapped resource for the implementation of IPE activities. ${ }^{12}$ Near-peer teaching is defined as an educational approach that encourages the development of knowledge through the support of peers who share many commonalities, such as being enrolled in similar courses or programs, but at different stages of learning. ${ }^{13,14}$ This approach is considered to be effective as near-peer tutors and tutees communicate more efficiently than teachers and students, due to their cognitive congruence and minimal social distance. ${ }^{15,16}$ Furthermore, the act of teaching requires a deeper learning of the subject and encourages tutors to direct and scale their communication to an appropriate audience. $^{17}$

Recent studies have demonstrated that using gross anatomy dissection as an IPE venue fosters positive attitudes toward other health professional students and enhances teamwork and communication skills. ${ }^{12,18,19}$ By identifying common grounds and complementarities in their knowledge of anatomy, students from different professional programs can better understand each other's professional scope and improve their clinical collaboration. ${ }^{3,4,20-22}$ Shields, Pizzimenti, Dudley-Javoroski, Schwinn ${ }^{12}$ demonstrated that such activities between medicine and physical therapy programs successfully fostered discussions about each profession's approach to learning about anatomy. Although recent studies have used near-peer IPE activities, their focus has been on reporting the learning outcomes, general participant appreciation and the perceived communication between participants. ${ }^{6}$ Until now, little has been done to establish the consistent criteria required for the sustainable design and implementation of such activities. ${ }^{6,23,24}$ In fact, very few studies have focused on examining the dynamics between the nursing-medical student dyad, particularly during gross anatomy IPE sessions. Consequently, recognizing near-peer IPE as a method to foster positive interprofessional role perceptions and communication among healthcare students, the current study aimed to assess how an anatomy interprofessional near-peer learning activity (AIP-NPLA) can be implemented by addressing the following topics: (1) identify key factors of feasibility, such as tutor-to-tutee ratio, readiness to engage in IP activities, optimal pairing of studentgroups based on professional background and student group dynamics, and (2) describe student-group perceptions of their experience in the gross anatomy laboratory.

\section{Materials and methods}

\section{Ethical considerations}

The University Institutional Review Board, in Montreal, Québec, Canada (IRB Study Number A11-E91-14B), gave ethical approval. Students participated in the AIP-NPLA on a voluntary basis. Informed consent was obtained from all responding students.

\section{Anatomy interprofessional near-peer learning activity (AIP-NPLA): description of student participants and the activity design and implementation}

Four AIP-NPLA sessions between undergraduate medical and nursing students were organized over the course of one academic year; two sessions in the fall semester with the remaining two sessions organized in the winter semester. All students who participated in the AIPNPLA did so on a voluntary basis. A combined total of 59 medical students in first- (Med 1) and second-year (Med 2) of medical school (out of 476 students enrolled) participated in the AIP-NPLA and were concurrently completing anatomical dissections of differing body regions as a component of their medical curricula. Nursing students were comprised of two groups, those registered in the Bachelor of Nursing (Integrated) (BNI) stream and those registered in the Bachelor of Science (Nursing) (BScN) stream. BNI students are those who have completed a three-year post-secondary certificate in nursing and have obtained their professional license. $\mathrm{BScN}$ student entrants have completed a two-year post-secondary science certificate and are at a pre-licensure stage during this time. The two nursing streams differ in that post-licensure BNI students enter this program having had clinical experiences whereas prelicensure $\mathrm{BScN}$ students have not yet been exposed to 
clinical practise. Both BNI and $\mathrm{BScN}$ students were in the first year of their respective programs and registered in a Health and Physical Assessment course. Of the 300 students registered in this course, 179 students from both streams participated in the AIP-NPLA.

Prior to each AIP-NPLA session, nursing students attended a two-hour preparatory anatomy lecture given by a faculty professor while medical students were required to attend a $30 \mathrm{~min}$ briefing on their role as facilitators in the AIP-NPLA. During the two-hour AIP-NPLA, medical students presented the age, sex and cause of death of the donor cadaver of which they previously performed dissections on as part of their medical school curricula to their nursing colleagues. The AIP-NPLA allowed for medical and nursing students to interact in the anatomy laboratory in groups consisting of a ratio of 1-2 medical students to 10-15 nursing students. The pairing of student groups was as follows: (1) Med 1 students with BNI students alone, (2) Med 2 students with BNI students alone, (3) Med 1 students with BScN alone and (4) Med 1 students with combined BNI and $\mathrm{BScN}$ students (see Figure 1).

\section{Study respondents}

Of the 59 medical students who were involved in the AIPNPLA, six Med 1 students and six Med 2 students consented to participate in this investigation. Of the nursing students who participated in the AIP-NPLA, 174 combined BScN and BNI students consented to participate in this investigation. All study participants were asked to complete the surveys listed below. Students participating in the focus group interviews consisted of 12 medical students ( 6 Med 1, 6 Med 2) and a combined group of $20 \mathrm{BNI}$ and $\mathrm{BScN}$ students. Separate focus group interviews were conducted for each student group.

\section{Data collection}

A convergent parallel (concurrent triangulation) mixed methods study was employed for collecting, analyzing, and interpreting quantitative and qualitative data sets, providing for an in-depth understanding of the students' unique perspectives and experiences. ${ }^{25}$ All participants in 2015-2016 were asked to complete a group of previously validated surveys prior to or following the activity. ${ }^{26-29}$ The following surveys permitted the authors to identify key feasibility factors:

(1) the Readiness for Interprofessional Learning Scale (RIPLS) $^{27}$ was used to identify the level of nursing and medical students' readiness, and internally validated (Cronbach's alpha of 0.88), to engage in IPE activities by measuring characteristics such as teamwork and collaboration, shared learning and common learning environments for different health professional students using a 5point Likert scale, with a score of 1 being "strongly disagree" to 5 being "strongly agree"; 27

(2) the Professional Self-Identity Questionnaire (PSIQ) ${ }^{30}$ provides an indication as to how closely each student selfidentifies as being part of a professional group using a 7-point Likert scale with statements ranging from "not much at all" to "a great deal". This questionnaire was used to assess if self-identity scores can predict optimal group pairing and was internally validated (Cronbach's alpha of 0.83 );

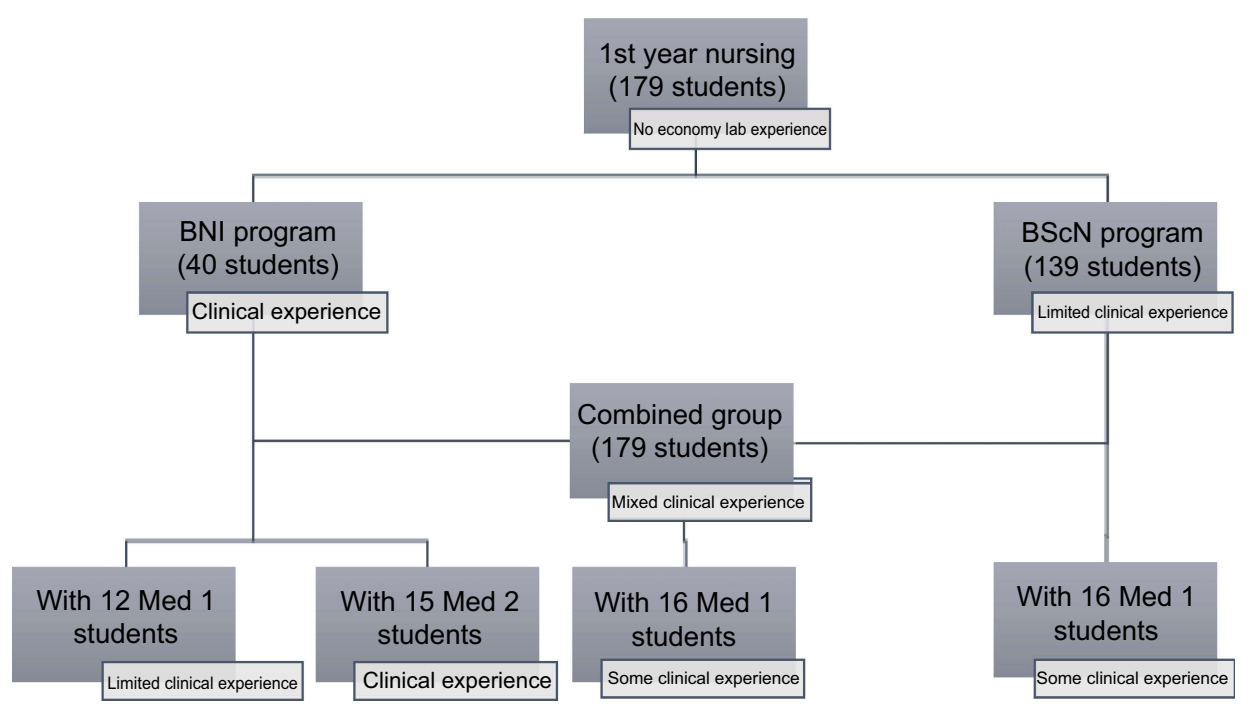

Figure I Distribution of student participation in the AIP-NPLA. 
(3) the Clinical Teaching Preference Questionnaire $(\mathrm{CTPQ})^{31}$ was also bused to determine if a near-peer learning strategy was appropriate for the implementation of an AIP-NPLA and was internally validated (Cronbach's alpha of 0.76) and

(4) the Peer Teaching Experience Questionnaires (PTEQ) $^{32}$ was also bused to determine if a near-peer learning strategy was appropriate for the implementation of an AIP-NPLA and was internally validated (Cronbach's alpha of 0.60).

The CTPQ specifically focuses on the effect of peerassisted learning on the peer-learner while the PTEQ focuses on the experience of the peer-teacher. Given this, the CTPQ was completed by the nursing students (ie the peer learners in this investigation) and the PTEQ was completed by the medical students (ie the peer teachers in this investigation) alone. Both Questionnaires utilize a 5-point Likert scale with 1 being "strongly disagree" to 5 being "strongly agree".

To assess the implementation of the AIP-NPLA and further understand key factors regarding its feasibility, both medical (Med 1 and Med 2) and nursing (BScN and BNI) students, were invited to separate, informal focus group interviews following their participation in the activity. Each session followed a semi-structured discussion format that was audio-recorded and later transcribed. Group consent for the recording was obtained verbally and captured on the recording. Discussion questions and prompts aimed to explore the students' experience of their interaction with their paired interprofessional student counterparts, and their general perceptions of the activity.

\section{Data analysis \\ Quantitative analysis}

GraphPad Prism 6 was used for all statistical analyses conducted in this study. Scores for each survey were summed separately. Descriptive statistics, such as means and standard error of the mean (SEM), were used to describe the individual groups on each of the measured variables. An unpaired, twotailed Student's $t$-test was used to compare student groups and identify the significant differences among the groups. A $p$ value cut-off of $\leq 0.05$ was used to indicate statistical significance between data sets. To further validate the significance, a Bonferroni correction was performed to adjust for multiple comparisons. ${ }^{33}$ The new type I error rate is set to be at 0.05 , divided by the number of questions in each survey to be considered statistically significant.

\section{Qualitative analysis}

Thematic content analysis was used to generate the codes, themes, and patterns that captured the students' experiences during the AIP-NPLA. ${ }^{34}$ Investigator triangulation ensured the trustworthiness of the findings. ${ }^{35}$ Excerpts from the focus group interviews were grouped into broader categories and were subsequently collapsed into three major themes: learning from one another, factors for a successful learning activity, and thoughts on interprofessional stereotypes.

\section{Results}

\section{Medicine and nursing students demonstrated a readiness to engage in the AIP-NPLA and describe the experience positively both quantitatively and qualitatively Quantitative summary}

Prior to engaging in the AIP-NPLA, all students were asked to complete the RIPLS. Overall, all groups of students were equally ready to engage in the AIP-NPLA as represented by the mean scores and standard error for each category of students; Med 1: $73 \pm 1.30$; Med 2: 76.8 \pm 1.39 ; BNI: 73.6 \pm 0.86 ; and $\mathrm{BScN}$ : $73.8 \pm 0.51$. A maximum score of 95 on this survey indicates the highest and most positive views towards interprofessional engagement.

As tutors in this peer-teaching activity, both Med 1 and Med 2 students completed the PTEQ (results displayed in Table 1). With the exception of one questionnaire item (item 4), all medical student scoring on the PTEQ was positive, suggesting that the effort and time put towards this activity was rewarding, enjoyable, valuable, and time well spent with their nursing counterparts. Additionally, for most PTEQ items, the comparison of Med 1 and Med 2 student scoring demonstrated no statistical significant differences. An exception to this was observed for two questionnaire items. For item 4, "I was initially apprehensive about the interprofessional near-peer teaching opportunity", Med 2 students scored significantly lower than their Med 1 counterparts $(1.75 \pm 0.48 ; 3.0 \pm 0.45$ respectively, $p=0.0451$ ). For item 13, "Did you learn more about the topic by participating as a near-peer instructor?", the Med 2 students scored significantly higher than the Med 1 students (5.0 $\pm 0.0 ; 4.4 \pm 0.4$ respectively, $p=0.0315$ ). Those two items on the PTEQ that were associated with significantly different responses between Med 1 and Med 
Table I Medical student (Med I and Med 2) survey response data from the Peer Teaching Experience Questionnaire (PTEQ), Copyright (C) 1986. John Wiley and Sons. Adapted from Brown R, Condor S, Mathews A, Wade G, Williams J. Explaining intergroup differentiation in an industrial organization. J Occup Psychol. 1986;59(4):273-286. ${ }^{30}$ Data is reported as mean and standard error (S.E.). The asterisks represent statistically significant differences from Med I assessed by Student's $t$-test $\left({ }^{*} p<0.05\right)$. After Bonferroni correction with the level of significance adjusted from 0.05 to $0.05 / 13=0.0038$, no significant differences were found between survey responses obtained among the Med I and Med 2 students

\begin{tabular}{|c|c|c|c|c|}
\hline \multirow[t]{2}{*}{ Peer Teaching Experience Questionnaire (PTEQ) } & \multicolumn{2}{|c|}{ Med I } & \multicolumn{2}{|c|}{ Med 2} \\
\hline & Mean & S.E. & Mean & S.E. \\
\hline I. Teaching is an important role for a physician & 4.8 & 0.2 & 4.75 & 0.25 \\
\hline 2. The interprofessional near-peer teaching experience was time and effort well spent & 5.0 & 0.0 & 5.0 & 0.0 \\
\hline 3. The interprofessional near-peer teaching experience was personally rewarding & 4.6 & 0.24 & 5.0 & 0.0 \\
\hline 4. I was initially apprehensive about the interprofessional near-peer teaching opportunity & 3.0 & 0.45 & $1.75 *$ & 0.48 \\
\hline 5. I felt comfortable teaching the nursing students teaching basic anatomy & 4.4 & 0.24 & 4.5 & 0.29 \\
\hline 6. The interprofessional near-peer teaching experience allowed me to reflect on my own previous learning & 4.8 & 0.2 & 4.75 & 0.25 \\
\hline 7. I enjoyed working with the nursing students & 4.8 & 0.2 & 5.0 & 0.0 \\
\hline 8. I would be more confident teaching a clinical skill after this experience & 4.4 & 0.24 & 4.75 & 0.25 \\
\hline 8. There should be more opportunities for interprofessional near-peer teaching in the curriculum & 5.0 & 0.0 & 5.0 & 0.0 \\
\hline 9. Overall, did you enjoy teaching nursing students in this setting? & 5.0 & 0.0 & 5.0 & 0.0 \\
\hline 10. Overall, did you feel helpful/useful as a near peer instructor? & 4.4 & 0.24 & 4.75 & 0.25 \\
\hline II. Did you feel sufficiently knowledgeable to be teaching this topic to this audience? & 4.2 & 0.2 & 4.5 & 0.29 \\
\hline 12. Did you learn more about the topic by participating as a near peer instructor? & 4.4 & 0.4 & $5.0 *$ & 0.0 \\
\hline
\end{tabular}

2 students warrant further consideration, as with Bonferroni correction, no significant differences were found in comparing any of the survey items between the two groups of students.

Analysis of the CTPQ demonstrated differences between the responses of BNI and $\mathrm{BScN}$ student groups (see Table 2). Nursing students from both programs scored similarly (ie no statistical significance was observed) apart from questionnaire item 11, "both near-peer teaching sessions provided me with alternative strategies to correctly identify important anatomical concepts" and questionnaire item 15, "the amount of time devoted to the anatomy laboratory was too much". For questionnaire item 11, BNI students scored significantly higher than $\mathrm{BScN}$ students $(4.39 \pm 0.12 ; 3.89 \pm 0.19$ respectively, $p=0.0026$ ), demonstrating a more positive response to the activity with BNI students. For questionnaire item $15, \mathrm{BScN}$ students scored significantly higher than BNI students $(2.80 \pm 0.26 ; 1.77 \pm 0.18$ respectively, $p=0.0013)$. After Bonferroni correction with the level of significance adjusted from 0.05 to $0.05 /$ $16=0.0031$, the statistical differences observed in items 11 and 15 were maintained.

Overall, results from the CTPQ highlight that students from both $\mathrm{BScN}$ and $\mathrm{BNI}$ programs felt that the activity increased their interaction, collaboration, and communication with other students in a fashion that was more beneficial than being taught solely by their instructor. More importantly, BNI and $\mathrm{BScN}$ students reported that the activity allowed them to gain a better understanding of the importance of anatomy for future interprofessional collaborations in a clinical setting. The above-mentioned perceptions expressed quantitatively were also broadened qualitatively, via the focus group interviews held with both medical and nursing students separately.

\section{Qualitative summary: learning from one another}

Analyses of the focus group interviews demonstrated the positive aspects of learning from one another, a main theme expressed throughout the interview transcripts. Many nursing students elaborated on the benefits of nearpeer teaching by communicating that, "it wasn't unidirectional teaching. We could share our knowledge too, and I felt it was very appreciated by the medical students." Students also described the collaboration in the anatomy lab as unique, in that each student group felt that they had different, but equally important, contributions to offer for the benefit of the AIP-NPLA. During the nursing students' focus group interview, one student articulated that "the med students were asking [them] questions ... they showed us anatomy, but we also showed them things they did not know yet. We all had different experiences to bring to the table." Student views on effective learning 


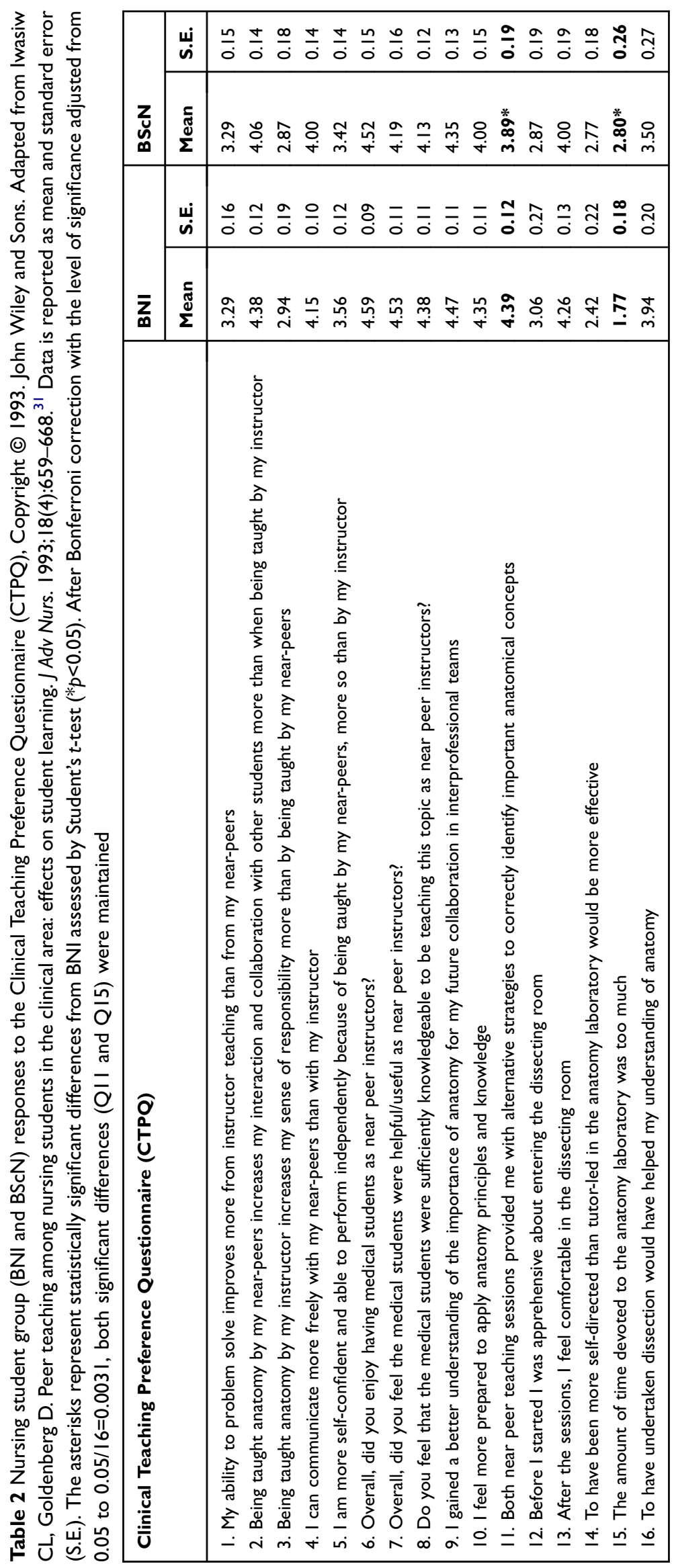


were also communicated and can be summarized by the following quote from a nursing student: "we got to pair up our views ... this is much more effective in learning interprofessionalism because we get to compare how they learn about the same thing." Similarly, medical students shared the same ideas by voicing that "interacting with nurses gives you a different perspective on the things we learn."

\section{Two key factors contributed to the success of the AIP-NPLA; student professional identity scores and student group interaction \\ Professional identity}

Prior to engaging in the AIP-NPLA, students were asked to report on their sense of professional self-identity by completing the PSIQ. A maximum score of 50 on the PSIQ indicates the strongest level of professional self-identify. In this investigation, the overall mean PSIQ scores and standard error calculations observed for each student group correlated to the amount of clinical exposure prior to the start of the AIP-NPLA. The BNI students scored highest (43.5 \pm 1.29$)$, having already begun the practice of nursing, followed by second-year medical students $(34.6 \pm 2.42)$, as they also had begun some of their clinical rotations. Firstyear medical students and first-year $\mathrm{BScN}$ students scored lower on the PSIQ, $23.75 \pm 4.4$ and $28.8 \pm 1.14$ respectively, having had minimal clinical exposure in their respective fields. When comparing student group responses for individual PSIQ items, medicine (Med 1 and Med 2) and nursing students (BNI and $\mathrm{BScN}$ ) responded consistently to all questionnaire items with the exception of item 7 ,"When I

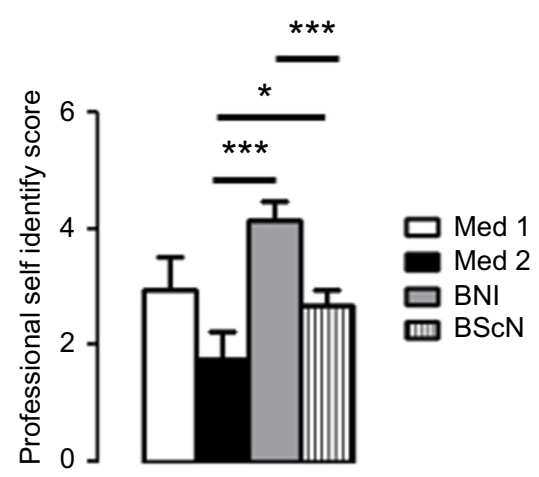

Figure 2 Distribution of the scores for question 7 of the Professional Self-Identity scale. The asterisks represent statistically significant differences from Med I assessed by Student's $t$-test $(* p<0.05 ; * * *<<0.0001)$. After Bonferroni correction with the level of significance adjusted from 0.05 to $0.05 / 9=0.005$, the significant differences found between survey responses obtained among the Med 2 and $\mathrm{BNI}$ and $\mathrm{BNI}$ and $\mathrm{BScN}$ were maintained. find myself in an emergency involving a patient or client, I feel like a 1st day student [score 1] or a qualified professional [score 5]". For this item, Med 2 students scored significantly lower than $\mathrm{BNI}$ and $\mathrm{BScN}$ students $(p<0.001$ and $p<0.05$, respectively). Furthermore, $\mathrm{BScN}$ students also scored significantly lower than BNI students $(p<0.0001)$ (see Figure 2). After Bonferroni correction, with the level of significance adjusted from 0.05 to $0.05 / 9=0.0051$, the significant differences found between Med 2 and BNI and between $\mathrm{BNI}$ and $\mathrm{BScN}$ were maintained.

\section{Interactivity between groups}

Each student group was asked to rate the knowledgeability of the two other student groups. It was found that BNI students were the only participants that could effectively compare their experience with the Med 1 and the Med 2 students. Our observations demonstrated that BNI students perceived the Med 2 students to exude more experience and to have advanced teaching and presentation skills which helped to enhance student learning in the laboratory in comparison to the group of Med 1 students (4.63 \pm 0.13 toward Med 2 compared to 4.30 \pm 0.17 toward Med 1, $p=0.0327$ ) (see Table 3). This was further reflected by comments made in the BNI focus group interview such as, "it would have been interesting to have more experienced med students (not year 1 's) because they are more aware of what nurses know and value us more." When asked to compare their experience with Med 1 alone or with BNI combined, BScN students reported that the interaction was not as well received when BNI students were included in the mixed groups. However, the Med 1 did not score this question as low (Table 4, 3.14 \pm 0.14 from Med 1 compared to 2.27 \pm 0.30 from $\mathrm{BScN}, \quad p=0.0008)$. After Bonferroni correction with the level of significance adjusted from 0.05 to $0.05 / 6=0.0083$, the significant difference found for Question 4 in Table 4 was maintained.

An additional observation that emerged from the quantitative data revolved around optimal group size and student group ratios. Overall, students rated the smaller group experience more positively, particularly when there were 10 students per cadaver. The optimal ratio of medical to nursing students observed was one to eight (see Table 4) (3.50 \pm 029 from $\mathrm{BScN}$ and $4.00 \pm 0.40$ from Med 1). This was highlighted by the following student statement, "I don't know if smaller ratio nursing versus med student is possible, but that would be more interactive, and we would have clearer access to cadavers." 

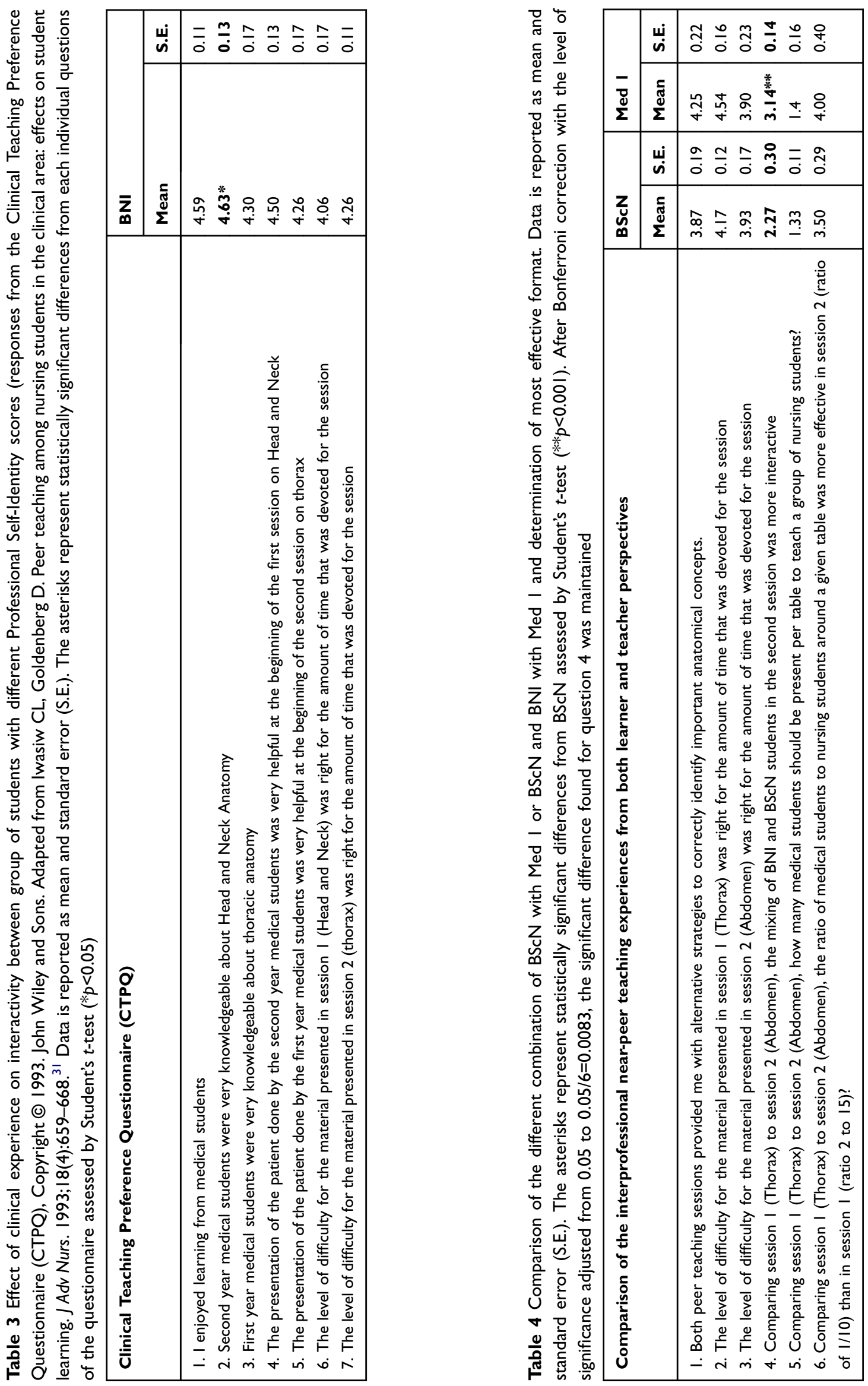
Throughout the activity, nursing students found their experience optimized when medical students were asking them questions, asking them to share their knowledge, and engaging them to manipulate anatomical parts during the session. Likewise, the medical students' experience was enhanced when nursing students were interacting and sharing their clinical knowledge during the activity. This is best represented by the following quote shared by a medical student, "it was enjoyable to draw correlates between the anatomy being demonstrated, and clinical scenarios that some of the nursing students have seen in hospital." Another medical student also commented on "wanting more interactions where the nursing students would take on a leading role."

\section{Thoughts on interprofessional stereotypes}

During their informal focus group interview, nursing students described the dynamics of the exchanges that were occurring during the AIP-NPLA. All students shared a common perception of a flat hierarchy and a respectful environment. The following quotes are representative of this emerging qualitative theme, "we had a discussion, I felt respected, I felt on the same level." Another student shared,

there [has] always been this hierarchy that people have internalized [between med and nursing students] ... The hierarchy wasn't as prominent [in the activity]. I really felt that it was very much on the same level.

Nursing students continued to articulate the realization that the AIP-NPLA brought to light assumptions they had about their counterparts and, for some, the activity might have affected some preconceived ideas. One nursing student summarized this thought with the following comment, "there is this assumption that the med students are high and mighty ... this activity decreased that stigma." Furthermore, many nursing students reflected on AIPNPLA's potential for improving preconceived stereotypes that medical students may have toward nursing. For example, students expressed that "the med students also got a perspective on us. Some were surprised that we knew this stuff. We hope they see that nursing students develop just like them and that we also have the knowledge." Although this theme was not initially sought out, both nursing and medical students discussed and reflected on the benefits of this approach to interprofessional teaching and learning.

\section{Discussion}

In designing interprofessional near-peer teaching initiatives, it is important to carefully consider a few variables: the level of clinical exposure of different healthcare groups, their professional identity formation and curricular milestones, the timing at which such interactions should occur, the educational format, and student characteristics. . $^{23,36,37}$ There are many contradictions in the literature regarding the effectiveness of early exposure to IPE. ${ }^{1}$ Some investigations have shown that early IPE exposure hinders the development of professional identity, ${ }^{38}$ while other authors report that early and repeated occurrences of this type of learning strategy help students develop an appreciation and understanding for the roles of other healthcare professionals. ${ }^{24,39}$ In this investigation, the assessment of student professional self-identity scores revealed that grouping students with similar scores or clinical exposure determined the effectiveness of the exercise. Student groups who scored equally on the professional self-identity scale and exhibited a similar level of clinical exposure, reported more satisfaction and interactivity during the AIP-NPLA when paired together. Student pairings combining second-year medical students with post-licensure nursing students, and firstyear medical students with pre-licensure nursing students were deemed to be the most effective formats for this exercise. Therefore, the introduction of IPE activities early in the professional training of both medical and nursing students could be beneficial, granted that the professional self-identity scores of the participants involved are not too distinct.

In addition to student group pairings, the tutor-to-tutee ratio appeared to be another defining variable for the success of the activity. In the current study, a ratio appreciated by both student populations included two tutors to a maximum of 15 tutees at one time. This is consistent with a systematic review by Gershenfeld ${ }^{40}$ which reported higher student satisfaction and more effectiveness of peer-learning approaches when ratios were low, specifically one tutor for a maximum of six to eight tutees.

The authors believe that the success of the IPE activity was, in part, because the in-lab format utilized was informal, flexible, and a free forum for student discussion. In a study by Lotrecchiano, McDonald, Lyons, Long, Zajicek-Farber, ${ }^{41}$ the use of informal forums of discussion combined with learning assignments for IPE facilitated interprofessional communication and continuous engagement. In this design, medical student tutors were encouraged to develop their own teaching strategies and be creative in their lesson plans for the 
activity, while maintaining clear learning objectives and a goal-oriented task to keep students on track during the activity. Furthermore, placing a topic of common knowledge between two health professions brought students together to create meaningful discussion outside of the clinical setting. ${ }^{42}$ This is of great importance, as others have also demonstrated that interprofessional activities do not need to revolve around a clinical setting in order to be successful. ${ }^{43,44}$ During the focus group interviews, students unexpectedly elaborated on the influence the AIP-NPLA had on stereotypical views of one another's profession and professional knowledge. Previous observations have demonstrated that students enter their professional training programs with preconceived notions of the roles and knowledge base of each type of healthcare professional. These stereotypes can be further reinforced during their unidisciplinary curricular programs. ${ }^{45,46}$ Some studies have shown that IPE activities can either enhance $^{45,47}$ or set aside ${ }^{1,48-51}$ those preconceived negative stereotypes as a result of their design. The design and approach of the current AIP-NPLA may have contributed to the perceived flat hierarchy expressed by nursing and medical student participants. The use of anatomy as a common knowledge base in both professional curriculums fostered a respectful and equal exchange between students, in addition to allowing for an improved understanding of each other's professional roles, capacity, and contribution to effective healthcare delivery.

\section{Limitations}

The current study has shown the feasibility of an anatomy IPE activity for a large cohort, considering the mobilization and coordination of the large number of participants in a gross anatomy laboratory. These numbers are reflective of the average student enrolment in most undergraduate health science programs. Although this study has demonstrated successful strides to promote the use of anatomy-based interprofessional activities, there are some limitations to discuss. In comparing the survey response rates, the response rate of the medical students was low. This may be attributed to scheduling issues, with the medical classes and students not being available to participate in the focus group interviews. Furthermore, given the voluntary nature of student participation in this study, the data may not be representative of the general population of nursing and medical students due to potential self-selection biases. Lastly, the current investigation utilized a unidirectional teaching format, whereby one group of students took on the role of tutor and the other of tutee. Recommendations for future studies include integrating a bidirectional format of near peer-teaching, whereby each student group takes on the roles of both tutor and tutee.

\section{Conclusion}

Overall, the interprofessional near-peer teaching approach transpired to be a beneficial activity for tutors and tutees, as both student groups expressed an appreciation of the commonalities and complementarities between their professions. The identification of preferred student group ratios and student group pairing based on professional self-identity scores has allowed the authors to describe, for the first time, various aspects of near-peer teaching activities that should be considered in the development of interprofessional education. The authors have further been able to demonstrate the successful implementation of an early interprofessional activity with a large participant number of medical and nursing students in the anatomy laboratory. The current study did not aim to explore notions of professional stereotypes. However, these reflections arose spontaneously. Future research may elaborate on this concept and how these stereotypes may be influenced by the participation in IPEAs of a similar design.

\section{Lessons learned}

- Interprofessional activities introduced early in the curriculum can be beneficial when designed appropriately.

- A successful group ratio for a near-peer teaching activity is one tutor to a maximum of six to eight tutees.

- The professional self-identity scores can be a valuable tool to find the best interprofessional group pairing.

- The design of informal/free forum lab discussions around the anatomy lessons allowed for successful communication amongst nursing and medical students.

- Well planned interprofessional teaching approach can mitigate some negative stereotypes nurses and medical students have of one another.

\section{Acknowledgments}

The Jonathan Campbell Meakins \& Family Memorial Fellowship, McGill University, Centre for Medical Education, supported this work. In addition, the authors would like to thank all the students that participated in this investigation. 


\section{Disclosure}

The authors report no conflicts of interest in this work.

\section{References}

1. Zwarenstein M, Reeves S. Working together but apart: barriers and routes to nurse-physician collaboration. Jt Comm J Qual Saf. 2002;28(5):242-247.

2. Gilbert JH, Yan J, Hoffman SJ. A WHO report: framework for action on interprofessional education and collaborative practice. $J$ Allied Health. 2010;39(3):196-197.

3. Barr H. Interprofessional Education: 1997-2000: A Review. London: CAIPE; 2000.

4. Reeves S, Zwarenstein M, Goldman J, et al. Interprofessional education: effects on professional practice and health care outcomes. Cochrane Database Syst Rev. 2008;1:1.

5. McLelland G, McKenna L, French J. Crossing professional barriers with peer-assisted learning: undergraduate midwifery students teaching undergraduate paramedic students. Nurse Educ Today. 2013;33 (7):724-728. doi:10.1016/j.nedt.2012.10.016

6. Abu-Rish E, Kim S, Choe L, et al. Current trends in interprofessional education of health sciences students: a literature review. $J$ Interprof Care. 2012;26(6):444-451. doi:10.3109/13561820.2012.715604

7. Horsburgh M, Lamdin R, Williamson E. Multiprofessional learning: the attitudes of medical, nursing and pharmacy students to shared learning. Med Educ. 2001;35(9):876-883.

8. Mitchell B, McCrorie P, Sedgwick P. Student attitudes towards anatomy teaching and learning in a multiprofessional context. Med Educ. 2004;38(7):737-748. doi:10.1111/j.1365-2929.2004. 01847.x

9. Chan S, Tsui K, De Meester L, et al. Dissecting through barriers: findings from a pilot study on the effect of interprofessional education in a gross anatomy course. MUMJ. 2011;8:11-15.

10. Morison S, Boohan M, Jenkins J, Moutray M. Facilitating undergraduate interprofessional learning in healthcare: comparing classroom and clinical learning for nursing and medical students. Learn Health Soc Care. 2003;2(2):92-104. doi:10.1046/j.1473-6861.2003.00043.x

11. Wilson T, Mires G. A comparison of performance by medical and midwifery students in multiprofessional teaching. Med Educ Oxford. 2000;34(9):744-746. doi:10.1046/j.1365-2923.2000.00619.x

12. Shields RK, Pizzimenti MA, Dudley-Javoroski S, Schwinn DA. Fostering interprofessional teamwork in an academic medical center: near-peer education for students during gross medical anatomy. Anat Sci Educ. 2015;8(4):331-337. doi:10.1002/ase.1466

13. Naeger DM, Conrad M, Nguyen J, Kohi MP, Webb EM. Students teaching students: evaluation of a "near-peer" teaching experience. Acad Radiol. 2013;20(9):1177-1182. doi:10.1002/ase.1539

14. Rashid MS, Sobowale O, Gore D. A near-peer teaching program designed, developed and delivered exclusively by recent medical graduates for final year medical students sitting the final objective structured clinical examination (OSCE). BMC Med Educ. 2011;11 (1):11. doi:10.1186/1472-6920-11-67

15. Youdas JW, Hoffarth BL, Kohlwey SR, Kramer CM, Petro JL. Peer teaching among physical therapy students during human gross anatomy: perceptions of peer teachers and students. Anat Sci Educ. 2008;1(5):199-206. doi:10.1002/ase.44

16. Lockspeiser TM, O'Sullivan P, Teherani A, Muller J. Understanding the experience of being taught by peers: the value of social and cognitive congruence. Adv Health Sci Educ. 2008;13(3):361-372. doi:10.1007/s10459-006-9049-8

17. de Oliveira CAM, de França Carvalho CP, Céspedes IC, de Oliveira F, Sueur-Maluf L. Peer mentoring program in an interprofessional and interdisciplinary curriculum in Brazil. Anat Sci Educ. 2015;8 (4):338-347. doi:10.1002/ase.1534
18. Fernandes AR, Palombella A, Salfi J, Wainman B. Dissecting through barriers: a mixed-methods study on the effect of interprofessional education in a dissection course with healthcare professional students. Anat Sci Educ. 2015;8(4):305-316. doi:10.1002/ase.1517

19. Smith CF, Hall S, Border S, Adds PJ, Finn GM. Interprofessional anatomy education in the United Kingdom and Ireland: perspectives from students and teachers. Anat Sci Educ. 2015;8(4):360-370. doi:10.1002/ase.1548

20. Sytsma TT, Haller EP, Youdas JW, et al. Long-term effect of a short interprofessional education interaction between medical and physical therapy students. Anat Sci Educ. 2015;8(4):317-323. doi:10.1002/ ase. 1546

21. McBride JM, Drake RL. Student perceptions of an interprofessional educational experience: the importance of goal articulation. Anat Sci Educ. 2015;8(4):381-385. doi:10.1002/ase.1547

22. Niekrash CE, Copes LE, Gonzalez RA. Frank Netter's legacy: interprofessional anatomy instruction. Anat Sci Educ. 2015;8(4):348-359. doi: $10.1002 /$ ase. 1540

23. Carpenter J. Interprofessional education for medical and nursing students: evaluation of a programme. Med Educ. 1995;29(4):265-272.

24. Hind M, Norman I, Cooper S, et al. Interprofessional perceptions of health care students. J Interprof Care. 2003;17(1):21-34.

25. Sandelowski M. Focus on research methods-whatever happened to qualitative description? Res Nurs Health. 2000;23(4):334-340.

26. Crossley J, Vivekananda-Schmidt P. The development and evaluation of a Professional Self Identity Questionnaire to measure evolving professional self-identity in health and social care students. Med Teach. 2009;31(12):e603-e607. doi:10.3109/01421590903193547

27. Parsell G, Bligh J. The development of a questionnaire to assess the readiness of health care students for interprofessional learning (RIPLS). Med Educ. 1999;33(2):95-100. doi:10.1046/j.1365-2923.1999.00298.x

28. Williams B, McKenna L, French J, Dousek S. The clinical teaching preference questionnaire (CTPQ): an exploratory factor analysis. Nurse Educ Today. 2013;33(8):814-817. doi:10.1016/j.nedt.2012.02.017

29. Williams B, McKenna L, French J, Dousek S. Measurement properties of a peer-teaching scale for nursing education. Nurs Health Sci. 2013;15(3):368-373. doi:10.1111/nhs. 12040

30. Brown R, Condor S, Mathews A, Wade G, Williams J. Explaining intergroup differentiation in an industrial organization. $J$ Occup Psychol. 1986;59(4):273-286. doi:10.1111/joop.1986.59.issue-4

31. Iwasiw CL, Goldenberg D. Peer teaching among nursing students in the clinical area: effects on student learning. J Adv Nurs. 1993;18(4):659-668.

32. McKenna L, French J. A step ahead: teaching undergraduate students to be peer teachers. Nurse Educ Pract. 2011;11(2):141-145. doi:10.1016/j.nepr.2010.10.003

33. Armstrong RA. When to use the Bonferroni correction. Ophthalmic Physiol Opt. 2014;34(5):502-508. doi:10.1111/opo.12131

34. Burnard P. A method of analysing interview transcripts in qualitative research. Nurse Educ Today. 1991;11(6):461-466.

35. Polit DF, Beck CT. Nursing Research: Principles and Methods. 7th ed. Philadelphia: Lippincott Williams \& Wilkins; 2004.

36. Hamilton SS, Yuan BJ, Lachman N, et al. Interprofessional education in gross anatomy: experience with first-year medical and physical therapy students at Mayo Clinic. Anat Sci Educ. 2008;1(6):258-263. doi:10.1002/ase.59

37. Thistlethwaite JE. Interprofessional education and the basic sciences: rationale and outcomes. Anat Sci Educ. 2015;8(4):299-304. doi:10.1002/ase. 1521

38. Wilbur K, Hasnani-Samnani Z, Kelly I. Interprofessional education activity among undergraduate nursing and pharmacy students in the Middle East. Nurse Educ. 2015;40(4):163-164. doi:10.1097/NNE.0000000000000135

39. Gould PR, Lee Y, Berkowitz S, Bronstein L. Impact of a collaborative interprofessional learning experience upon medical and social work students in geriatric health care. J Interprof Care. 2015;29 (4):372-373. doi:10.3109/13561820.2014.962128

40. Gershenfeld S. A review of undergraduate mentoring programs. Rev Educ Res. 2014;84(3):365-391. doi:10.3102/0034654313520512 
41. Lotrecchiano GR, McDonald P, Lyons L, Long T, Zajicek-Farber M. Blended learning: strengths, challenges, and lessons learned in an interprofessional training program. Matern Child Health J. 2013;17 (9):1725-1734. doi:10.1007/s10995-012-1175-8

42. Cleveland B, Kvan T. Designing learning spaces for interprofessional education in the anatomical sciences. Anat Sci Educ. 2015;8(4):371380. doi:10.1002/ase. 1539

43. Waterston R. Interaction in online interprofessional education case discussions. J Interprof Care. 2011;25(4):272-279. doi:10.3109/ 13561820.2011.566647

44. Morison S, Boohan M, Moutray M, Jenkins J. Developing pre-qualification inter-professional education for nursing and medical students: sampling student attitudes to guide development. Nurse Educ Pract. 2004;4(1):20-29. doi:10.1016/S1471-5953(03)00015-5

45. Cook K, Stoecker J. Healthcare student stereotypes: a systematic review with implications for interprofessional collaboration. $J$ Res Interprof Pract Educ. 2014;4:2. doi:10.22230/jripe.2014v4n2a151

46. Herrmann G, Woermann U, Schlegel C. Interprofessional education in anatomy: learning together in medical and nursing training. Anat Sci Educ. 2015;8(4):324-330. doi:10.1002/ase.1506
47. Harden RM. Interprofessional education: the magical mystery tour now less of a mystery. Anat Sci Educ. 2015;8(4):291-295. doi:10.1002/ ase. 1552

48. Ateah CA, Snow W, Wener P, et al. Stereotyping as a barrier to collaboration: does interprofessional education make a difference? Nurse Educ Today. 2011;31(2):208-213. doi:10.1016/j. nedt.2010.06.004

49. Coster S, Norman I, Murrells T, et al. Interprofessional attitudes amongst undergraduate students in the health professions: A longitudinal questionnaire survey. Int J Nurs Stud. 2008;45(11):16671681. doi:10.1016/j.ijnurstu.2008.02.008

50. Rudland JR, Mires GJ. Characteristics of doctors and nurses as perceived by students entering medical school: implications for shared teaching. Med Educ. 2005;39(5):448-455. doi:10.1111/ j.1365-2929.2005.02108.x

51. Stull CL, Blue CM. Examining the influence of professional identity formation on the attitudes of students towards interprofessional collaboration. J Interprof Care. 2016;30(1):90-96. doi:10.3109/ 13561820.2015 .1066318
Advances in Medical Education and Practice

\section{Publish your work in this journal}

Advances in Medical Education and Practice is an international, peerreviewed, open access journal that aims to present and publish research on Medical Education covering medical, dental, nursing and allied health care professional education. The journal covers undergraduate education, postgraduate training and continuing medical education

\section{Dovepress}

including emerging trends and innovative models linking education, research, and health care services. The manuscript management system is completely online and includes a very quick and fair peer-review system. Visit http://www.dovepress.com/testimonials.php to read real quotes from published authors. 